\title{
Determination of Picomole Quantitites of Hydroperoxides by a Coupled Glutathione Peroxidase and Glutathione Disulfide Specific Glutathione Reductase Assay
}

\author{
Kenneth G. D. Allen, ${ }^{1}$ Ching-Jang Huang, ${ }^{2}$ and Catherine L. Morin \\ Department of Food Science and Iuman Nutrition, Colorado State University, Fort Collins, Calorado 80523
}

Received October 10, 1989

A procedure to quantitate picomole amounts of hydroperoxides based on GSSG formation is described. Hydroperoxides are incubated with GSH and glutathione peroxidase, and the GSSG formed is measured by a GSSG-specific glutathione reductase recycling assay. Prior to analysis the remaining GSH is removed with $\boldsymbol{N}$-ethylmaleimide. $\boldsymbol{N}$-Ethylmaleimide inhibition of the recycling assay is prevented by alkaline hydrolysis of the $N$-ethyImaleimide, without GSSG hydrolysis, at $\mathbf{p H}$ 11. The method is rapid, $30 \mathrm{~min}$, with a limit of detection of 142 pmol calculated by linear regression analysis. Stoichiometric amounts of GSSG are produced in response to hydroperoxides. An application of the method is shown with air oxidation of arachidonic acid solutions over $4 \mathrm{~h}$ at room temperature. The method is sufficiently sensitive to quantitate the low amounts of hydroperoxides present in fresh arachidonic acid samples. (c) 1990 Academic Press, Inc.

Lipid peroxidation has been implicated in a variety of pathological processes $(1,2)$ and free fatty acid hydroperoxide concentrations control both the activation and the irreversible inhibition of prostaglandin $(\mathrm{PG})^{3} \mathrm{H}$ synthase, the common and rate-controlling step of tissue PG production $(3,4)$.

Numerous methods have been employed to detect the process of lipid peroxidation and to quantitate lipid hydroperoxide concentrations (1). However, most of these

\footnotetext{
${ }^{1}$ To whom reprint requests should be addressed.

${ }^{2}$ Present address: Department of Agricultural Chemistry, National Taiwan University, Taipei, Taiwan 10764, Republic of China.

${ }^{3}$ Abbreviations used: PG, prostaglandin; TBA, thiobarbituric acid; NEM, $N$-ethylmaleimide; DTNB, 5,5'-dithiobis(2-nitrobenzoic acid); 15-HPETE, 15-hydroperoxyeicosatetraenoic acid; BH'T, butylated hydroxytoluene.
}

methods lack sensitivity and measure either an early or a late stage in the peroxidation process. Nearly all commonly used quantitative methods fail to directly measure lipid hydroperoxides but rather measure decomposition products such as hydrocarbons or malondialdehyde (1,5-7). The TBA assay (5) has been used extensively to quantitate lipid peroxidation with detection limits reported as $0.1 \mathrm{nmol}$ for the fluorometric TBA assay (8). The TBA assay lacks sensitivity since many nonlipid components produce chromogens with TBA (5). Furthermore, this TBA assay measures the decomposition product, malondialdehyde, of only a fraction (less than 10\%) of lipid hydroperoxides, and the results are thus confusing since they imply at least 10 -fold higher lipid hydroperoxide concentrations (9).

This paper describes a routine assay for hydroperoxides that uses glutathione peroxidase generation of GSSG from GSH, followed by a GSSG-specific glutathione reductase-DTNB recycling assay. The detection limit for the assay is $142 \mathrm{pmol}$ of hydroperoxide with a sensitivity of less than $100 \mathrm{pmol}$. The assay is rapid, 30 $\mathrm{min}$, and an application is shown to the quantitation of hydroperoxides formed from arachidonic acid solutions exposed to air at room temperature.

\section{MATERIAL AND METHODS}

\section{Materials}

Glutathione peroxidase, glutathione reductase, GSH, GSSG, NEM, Tween 20 detergent, $\mathrm{KBH}_{4}, \mathrm{NADPH}$, DTNB, BHT, and $t$-butyl hydroperoxide were obtained from Sigma (St. Louis, MO). Arachidonic acid and 15HPETE were obtained from Cayman Chemical Co. (Ann Arbor, MI). Solvents for TLC and spectroscopic analysis (Fischer, Fair Lawn, NJ) were HPLC or spectroscopic grade. Silica gel plates (E. Merck silica gel 60) were obtained from Altech (Deerfield, IL). Hydrogen 
peroxide was obtained from Mallinckrodt (Paris, KY). All other reagents were analytical grade.

\section{Measurement of Hydroperoxides}

All solutions were made in $73 \mathrm{~mm}(\mathrm{Na})$ phosphate, 5 mM EDTA, $\mathrm{pH}$ 7.4, using distilled, deionized water $(<4$ $\mathrm{ng} / \mathrm{ml} \mathrm{Fe}$ and $\mathrm{Cu}$ ). All glass and plastic ware was routinely rinsed in $0.1 \mathrm{M} \mathrm{HCl}$ and soaked overnight in $2 \mathrm{mM}$ EDTA prior to rinsing.

Tubes containing 0 and a range of from 60 pmol to 4.5 nmol hydroperoxide, made by adding $t$-butyl hydroperoxide, 15-HPETE, or hydrogen peroxide, were incubated at $37^{\circ} \mathrm{C}$ (water bath) for $10 \mathrm{~min}$ with $50 \mu \mathrm{l}$ of $1 \mathrm{mM}$ GSH $(50 \mathrm{nmol})$ and $20 \mu \mathrm{l}$ of $10 \mathrm{U} / \mathrm{ml}(0.2 \mathrm{U})$ glutathione peroxidase in a total volume of $0.5 \mathrm{ml}$, the balance of the volume being phosphate buffer. Following incubation 50 $\mu \mathrm{l}$ of $125 \mathrm{mM}$ NEM (final concentration $12.5 \mathrm{mM}$ ) was then added with mixing and unreacted GSH derivatized for $15 \mathrm{~min}$ at room temperature. Excess NEM was then removed by the procedure of Sacchetta et al. (10) by addition of $4 \mu \mathrm{l} 8 \mathrm{M}$ aqueous $\mathrm{KOH}$ at room temperature for 5 min. This amount of $\mathrm{KOH}$ raised the $\mathrm{pH}$ to 11 , a $\mathrm{pH}$ at which NEM is hydrolyzed to $N$-ethylmaleamic acid without hydrolysis of GSSG (10). After 5 min samples were rebuffered to $\mathrm{pH} 7.4$ by addition of $8 \mu \mathrm{l} 4 \mathrm{M} \mathrm{HCl}$. Small volumes of concentrated $\mathrm{KOH}$ and $\mathrm{HCl}$ solutions were chosen since they could be delivered along the wall of the tube without entering the solution below until the tube was mixed by vortexing. This procedure was employed to avoid local extreme changes in $\mathrm{pH}$ since $\mathrm{pH}$ control is essential to limiting GSSG hydrolysis (10).

Samples were then analyzed by the glutathione reductase-DTNB recycling assay (11). Seven hundred microliters of $0.3 \mathrm{~mm} \mathrm{NADPH}, 100 \mu \mathrm{l}$ of $10 \mathrm{~mm}$ DTNB, and $200 \mu \mathrm{l}$ of incubated samples or blanks were placed in a $1-\mathrm{ml}$ cuvette. The reaction was started with $1.0 \mathrm{U}$ of glutathione reductase $(20 \mu \mathrm{l}$ of $50 \mathrm{U} / \mathrm{ml}$ solution) and the rate of change in absorbance at $412 \mathrm{~nm}$ with time measured using a recording spectrophotometer (Beckman, Fullerton, CA). In order to quantitate GSSG production in response to added peroxide, samples were also analyzed for GSSG using the recycling assay with a GSSG standard curve.

\section{Measurement of Hydroperoxides in Arachidonic Acid Solutions Exposed to Air}

Four separate batches of freshly obtained arachidonic acid were used. Upon receipt batches were analyzed for lipid hydroperoxides by TLC on silica gel using a 80:30: 2 hexane:diethyl ether:acetic acid solvent system which separates 15-HPETE from arachidonic acid. Only one component was observed with iodine visualization and no component was observed with the mobility of the 15HPETE standard. For each batch of arachidonic acid a solution ( $1 \mathrm{mg}$ in $1 \mathrm{ml}$ ethanol, $3.3 \mathrm{~mm}$ ) was analyzed for conjugated diene by spectroscopy (Gilford scanning spectrophotometer, Oberlin, $\mathrm{OH}$ ). No peak or shoulder was observed in the $230-235 \mathrm{~nm}$ range. On the basis of these analyses it was concluded that the arachidonic acid was free of hydroperoxides.

Aliquots of each of the four batches of arachidonic acid were dissolved in phosphate buffer, without EDTA, containing $5 \mu \mathrm{g}$ Tween $20 / \mathrm{ml}$ to provide $20 \mathrm{ml}$ of a 32.8 $\mu \mathrm{M}$ solution of arachidonic acid. This phosphate buffer solution was found to contain $2.6 \mu \mathrm{M}$ iron by atomic absorption spectrophotometry (Instrumentation Laboratories, Willmington, MA) by the method of standard additions. The $20-\mathrm{ml}$ solution were placed in $50-\mathrm{ml}$ beakers left exposed to air at room temperature without continuous stirring. Aliquots were removed at $0 \mathrm{~min}$ and 1,2 , and $4 \mathrm{~h}$ for analysis of lipid hydroperoxides as described. $t$-Butyl hydroperoxide was used for the standard curve, and a separate standard curve was run at each time point. At $4 \mathrm{~h}$ approximately $2 \mathrm{mg}$ of solid $\mathrm{KBH}_{4}$ was added to the solution and allowed to react for $20 \mathrm{~min}$ at room temperature. Excess $\mathrm{KBH}_{4}$ was removed by acidification with $\mathrm{HCl}$ followed by adjustment to $\mathrm{pH} 7.4$ with aqueous $\mathrm{KOH}$. Samples were then analyzed for lipid hydroperoxide as described. Triplicate samples of arachidonic acid solution were analyzed at each time point.

For one sample of arachidonic acid a bulk $32.8 \mu \mathrm{M}$ solution $(5 \mathrm{mg}$ in $500 \mathrm{ml}$ ) was prepared in phosphate buffer, without E'IA, and left at room temperature for $4 \mathrm{~h}$. This bulk solution was acidified to $\mathrm{pH} 2$ with $\mathrm{HCl}$ and extracted with hexane:diethyl ether, 1:1, and the extract evaporated (rotary evaporator) and redissolved in $1 \mathrm{ml}$ ethanol. The ethanol solution was scanned over wavelength range $220-290 \mathrm{~nm}$ and the spectra were compared to a fresh solution of $5 \mathrm{mg}$ arachidonic acid in ethanol. The extracted solution was also analyzed by TLC on a silica gel as described.

\section{RESULTS}

Figure 1 shows typical data obtained with standards of $t$-butyl hydroperoxide, 15-HPETE, and hydrogen peroxide. The assay is linear over the range $60 \mathrm{pmol}$ to 4.5 $\mathrm{nmol}$ (linear regression correlation coefficient, $r,>0.98$ ). The response of the three hydroperoxides used was essentially identical. The detection limit for the assay was determined according to the equation, detection limit $=Y_{\mathrm{B}}+2 S_{y / x}$ where $Y_{\mathrm{B}}$ is the $y$ intercept and $S_{y / x}$ the standard deviation from the linear regression of hydroperoxide ( $\mathrm{nmol}$ ) versus rate of absorbance change at 412 $\mathrm{nm}$ (12). Using this equation the detection limit obtained was $142.2 \pm 5.1$ pmol (mean $\pm \mathrm{SE}, N=6$ ) with no difference in detection limit for the three hydroperoxides used in standard curves. Sensitivity, measured as the change in absorbance rate at $412 \mathrm{~nm}$ in response to $100 \mathrm{pmol}$ of hydroperoxide (slope sensitivity), was 0.011 \pm 0.001 (mean $\pm \mathrm{SE}, N=6$ ).

Blank rates obtained in hydroperoxide assays (assay blanks) are typically in the range $0.09-0.12$ absorbance 


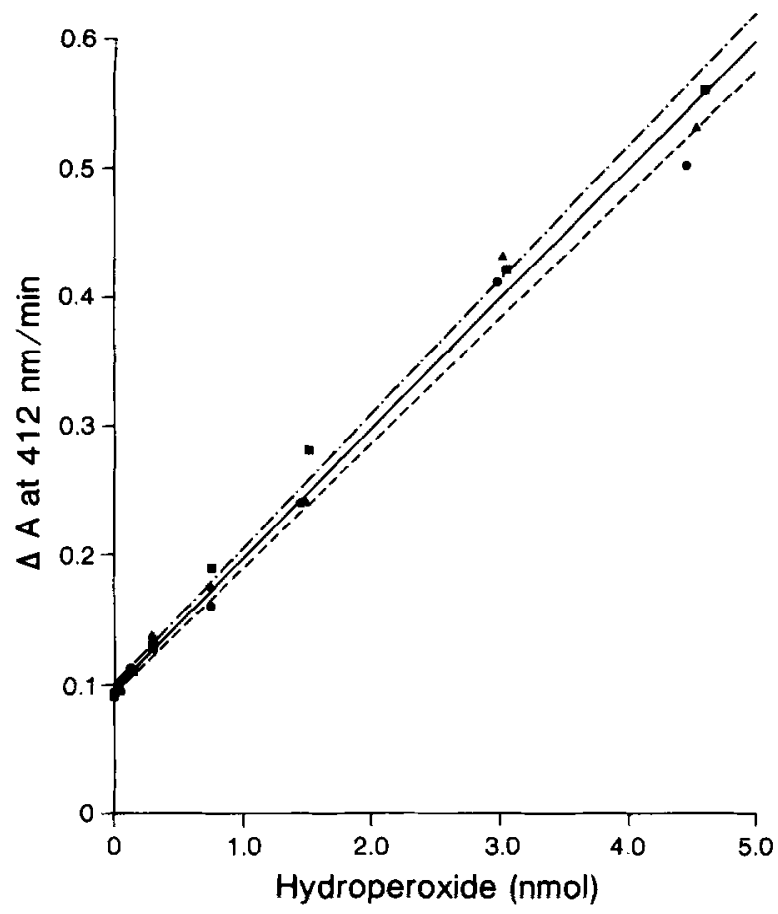

FIG. 1. Measurement of hydroperoxides: $(\bullet) t$-butyl hydroperoxide $(r=0.99)$; (৯) 15-HPETE $(r=0.99)$; ( $)$ hydrogen peroxide $(r=0.99)$; $r$ values by linear regression analysis.

unit/min at $412 \mathrm{~nm}$. This is considerably higher than blank rates for GSSG assays (buffer blanks) using this recycling assay (typically $0.03-0.05$ in our experience). The higher assay blank values are due to GSSG contamination of GSH and are predictable based upon this GSSG contamination. Air oxidation of GSH was not a problem in the buffer system used. Assay blanks run at the beginning and end of up to 40 tube assays vary by less than $10 \%$. The air oxidation of $50 \mathrm{nmol} \mathrm{GSH}$ in the phosphate buffer system used, an amount equal to that employed in the assay, was examined over $100 \mathrm{~min}$ at $37^{\circ} \mathrm{C}$ using a GSSG standard curve recycling assay following derivitization of GSH with NEM as described. Using this procedure GSSG contamination of GSH was determined to be $0.3 \mathrm{~mol} \%$ (as purchased) and did not increase until $40 \mathrm{~min}$. Since the hydroperoxide assay requires incubation with $50 \mathrm{nmol}$ of GSH for $10 \mathrm{~min}$ these results, in addition to the stability of assay blank values, indicate that air oxidation of GSH does not compromise the assay.

Both blanks and samples of hydroperoxides incubated with GSH but containing either no glutathione peroxidase or heat-denatured $\left(98^{\circ} \mathrm{C}, 15 \mathrm{~min}\right)$ glutathione peroxidase gave absorbance rate values equal to those of assay blanks. Omission of GSH in hydroperoxide samples, or blanks, containing either glutathione peroxidase or heat-denatured glutathione peroxidase gave absorbance rate values lower than those of assay blanks but equal to those of buffer blanks. These results show that there is no reaction between hydroperoxides and GSH in the ab- sence of active glutathione peroxidase and that the higher value of hydroperoxide assay blanks is due to GSSG contamination of GSH.

In several samples of hydroperoxides the amount of GSSG produced in response to added hydroperoxide was quantitated. The stoichiometry between added hydroperoxide and GSSG formed was determined to be 1:0.97 \pm 0.01 (mean $\pm \mathrm{SE}, N=12$ ) over the full assay range, with no difference between the peroxides used. Inclusion of $5 \mu \mathrm{g}$ Tween $20 / \mathrm{ml}$ or up to $20 \%$ ethanol in the buffer system did not influence the assay. Furthermore, $1 \mu \mathrm{M}$ $\mathrm{BHT}$ was without influence on the assay.

Figure 2 shows the results of air oxidation of four separate batches of $32.8 \mu \mathrm{M}$ arachidonic acid in phosphate buffer (no EDTA), $5 \mu$ g Tween $20 / \mathrm{ml}$. This phosphate buffer system was found to contain $2.6 \mu \mathrm{M} \mathrm{Fe}$, presumably as a contaminant of reagents. Replicate analyses of arachidonic acid samples gave a coefficient of variation of less than $10 \%$. Reduction of 4-h samples with $\mathrm{KBH}_{4}$ gave values equal to those of assay blanks. Additional evidence for peroxidation of arachidonic acid under these conditions is shown in Fig. 3. Spectroscopic analysis shows a shoulder at $235 \mathrm{~nm}$ indicative of conjugated dienes and TLC analysis shows the appearance of a component with the mobility of 15-HPETE. Other components, not identified, also appeared at $4 \mathrm{~h}$ and may be fragmentation products. These data, Fig. 3, support the interpretation of peroxidation of arachidonic acid under the conditions described.

\section{DISCUSSION}

This assay for lipid hydroperoxides is rapid, $30 \mathrm{~min}$, with a detection limit of $142 \mathrm{pmol}$. The assay is a direct measure of hydroperoxides rather than an indirect quan-

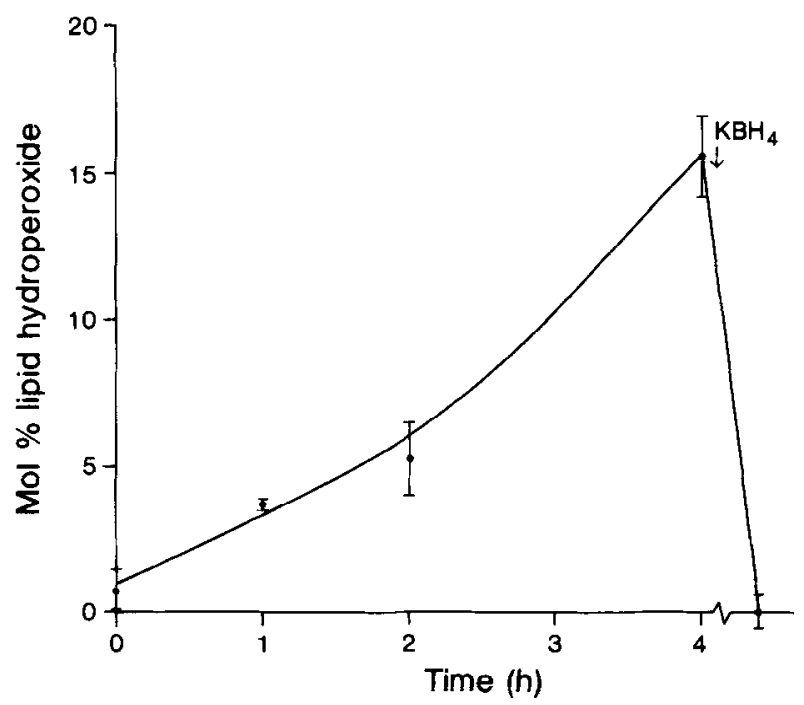

FIG. 2. Mole percentage lipid hydroperoxide (mean $\pm \mathrm{SE}, N=4$ ) in air-oxidized arachidonic acid solution. Arrow indicates $\mathrm{KBH}_{4}$ reduction of $4-\mathrm{h}$ oxidized samples. 




FIG. 3. (A) Scanning spectroscopy of $3.3 \mathrm{~mm}$ arachidonic acid (-.-) and 4-h oxidized arachidonic acid (-). (B) TLC of channel 1, arachidonic acid $(5 \mu \mathrm{g})$; channel 2 , 15-HPETE ( $5 \mu \mathrm{g})$; channel 3,4 -h oxidized arachidonic acid $(50 \mu \mathrm{g})$; channel 4,4 -h oxidized arachidonic acid (50 $\mu \mathrm{g}$ ) plus 15 -HPETE $(5 \mu \mathrm{g})$; channel 5,4 -h oxidized arachidonic acid $(50 \mu \mathrm{g})$ plus arachidonic acid standard $(5 \mu \mathrm{g})$. Solid spots, major components; open spots, minor components; with iodine visualization. SF, solvent front; $O$, origin.

titation based on the peroxidative process or the decomposition of peroxidation products. The assay is sufficiently sensitive to quantitate hydroperoxides in fresh samples of arachidonic acid and to measure increases in these hydroperoxides over a 4-h period. Hydroperoxide concentrations in freshly obtained arachidonic acid were in the range $0.3-0.9 \mathrm{~mol} \%$. Reduction of peroxidized arachidonic acid samples followed by analysis gave values equal to assay blanks. Spectroscopic and TLC analysis provide additional evidence of peroxidation of arachidonic acid.

The assay has similarities to that of Heath and Tappel (13) where lipid hydroperoxides were quantitated by incubation with glutathione peroxidase and GSH, and the GSSG produced measured spectrophotometrically at $340 \mathrm{~nm}$ by glutathione reductase-mediated loss of NADPH. However, with a molar extinction coefficient of $6.2 \times 10^{3}$ quantitation based on NADPH loss does not have the low detection limit of this assay. The assay of Heath and Tappel has a reported detection limit of 3 nmol whereas the assay based on GSSG analysis has a linear regression analysis calculated detection limit 142 pmol. Heath and Tappel reported GSH oxidation by air at a rate of $10^{-7} \mathrm{~mol} / \mathrm{min}$. However, based on assay blank stability and the direct measure of air oxidation of GSH the present assay is not compromised by air oxidation of GSH during the incubation phase. The difference may be due to $5 \mathrm{mM}$ EDTA used in the assay versus the 0.2 mM EDTA employed by Heath and Tappel.

The reagents used in this assay are freshly prepared on a daily basis. However, GSH solution is freshly prepared for each assay. We have found it convenient to store aliquots, 0.5 to $1.0 \mathrm{ml}$, of glutathione peroxidase $(10 \mathrm{U} / \mathrm{ml})$ in phosphate buffer at $-70^{\circ} \mathrm{C}$ and to thaw these aliquots as needed.

The method described has direct applications for determining hydroperoxide concentrations in polyunsaturated free fatty acid substrates for studies involving cyclooxygenase and lipoxygenase reactions, Lipid hydroperoxides are critical regulators of $P G H$ synthase $(3,4)$ and establishing their concentration in substrate samples is necessary. This assay is sufficiently sensitive to detect the small quantity of hydroperoxides in freshly obtained arachidonic acid samples. For tissue lipid hydroperoxide analysis it will be necessary to liberate fatty acids from the phospholipid prior to analysis since glutathione peroxidase shows activity with free fatty acid hydroperoxides but not with phospholipid hydroperoxides (14). Other direct measurements of lipid hydroperoxides have been reported with picomole detection limits $(9,15,16)$. However, they are relatively complicated in comparison to the assay described in this study.

\section{REFERENCES}

1. Halliwell, B., and Gutteridge, J. M. C. (1985) Mol. Aspects Med. 8, 89-193.

2. Simpson, P. J., Fantone, J. C., and Lucchesi, B. (1987) in Oxyradicals and Tissue Injury-Proceedings of an Upjohn Symposium (Halliwell, B., Ed.), pp. 63-77, Federation of American Societies for Experimental Biology, Bethesda, MD.

3. Lands, W. E. M., Kulmacz, R. J., and Marshall, P. J. (1984) in Free Radicals in Biology (Pryor, W. A., Ed.), Vol. 6, pp. 39-61, Academic Press, Orlando, FL.

4. Marshall, P. J., Kulmacz, R. J., and Lands, W. E. M. (1987) J. Biol. Chem. 262, 3510-3517.

5. Gutteridge, J. M. C. (1986) Free Radical Res. Commun. 1. 173-184.

6. Smith, C. V., and Anderson, R. E. (1987) Free Radical Biol. Med. 3, 341-344.

7. van Kuijk, F. J. G. M., and Dratz, E. A. (1987) Free Radical Biol. Med. 3, 349-354.

8. Yagi, K. (1976) Biochem. Med. 15, 212-216.

9. Marshall, P. J., Warso, M. A., and Lands, W. E. M. (1985) Anal. Biochem. 145, 192-199.

10. Sacchetta, P., DiCola, D., and Federici, G. (1986) Anal. Biochem. 154, 205-208.

11. Allen, K. G. D., and Arthur, J. R. (1987) Clin. Chim. Acta 162, 237-239.

12. Miller, J. C., and Miller, J. N. (1986) Statistics in Analytical Chemistry, p. 96, Wiley, Chichester.

13. Heath, R. L., and Tappel, A. I. (1976) Anal. Biochem. 76, 184191.

14. Ursini, F., Maiorino, M., and Gregolin, G. (1985) Biochim. Biophys. Acta 839, 62-70.

15. Funk, M. O. (1987) Free Radical Biol. Med. 3, 319-321.

16. Gut, J., Jamieson, G. C., and Trudell, J. R. (1987) Free Radical Biol. Med. 3, 323-328. 